\title{
Management of Appendicular Mass; Comparative Study between Different Modalities
}

\section{Elsaady A*}

Department of General Surgery, Kafr Elshikh General Hospital, Egypt

*Corresponding author: Ahmed Elsaady, Department of General Surgery, Kafr Elshikh General Hospital, Egypt

Received: November 22, 2018; Accepted: February 04, 2019; Published: February 11, 2019

\begin{abstract}
In spite of its commonality, there is no universal standard in the management of appendicular mass. This study is a prospective one, aiming at comparing the different modalities of management in terms of efficacy and safety.

Over seven years, all patients presented with appendicular mass were involved in the study, where they were divided into four groups; conservative management with routine interval appendectomy (group A), conservative treatment without interval appendectomy as a routine (group B), operative interference at the initial admission (group C), \& laparoscopic exploration (group D). The study assessed the efficacy, complications, difficulties encountered in operative groups, rate of recurrence, hospital stay, and durations of treatment.

169 cases were presented in this study. The conservative management was successful in about $88 \%$ patients Appendectomy was done in all patients of group A, C \& D, and only $18 \%$ in group B need appendectomy, Appendectomy was done in two settings (drainage then appendectomy) in $\sim 5 \%$ of group $A$, $\sim 4 \%$ of group B, $14 \%$ of group C, and $27 \%$ of patients in group D. The hospital stay \& duration of treatment were $>2$ folds more in conservative groups (A\&B) than intervention groups $(C \& D)$. Difficulties in operations were reported more in intervention groups (c \&d), where consultant was needed in all cases of group D, $2 / 3$ of group B , and only $1 / 3$ of group B \& $7 \%$ in group $A$. There was no significant difference in operative difficulties between patient failed conservative measures and interventional group from the start (group C\&D).

The study concluded that; although there is a debate in the best modalities of treatment of appendicular mass, the conservative approach is still a quite effective \& safe method of treatment, with no significant operative difficulties in failed group. The rate of recurrence after successful conservative management is low to justify interval appendectomy as a routine. CT \& or colonoscopy is preferred to be done after relief of acute attacks to avoid missing another pathology. The laparoscopic approach seem to be promising, with early recovery as well as diagnostic superiority for a hidden pathology. It may become the best modality with the growing of the learning curve.
\end{abstract}

Keywords: Appendicular Mass; Interval Appendectomy; Appendicitis

\section{Introduction}

Acute appendicitis is still one of the most common surgical emergencies [1], with an annual incidence rate of about $0.1 \%$ inhabitants [2]. Up to $10 \%$ of these cases may develop appendicular mass [3]. In spite of its commonality, there is no universal standard in the management of the appendicular mass [1], with wide variable options to the extreme. Four modalities were reported in literature from the traditional conservative approach either with or without interval appendectomy as a routine to interventional approach either open and or laparoscopic during the initial admission [4]. This study is a prospective one, aims at comparing the different modalities of management in terms of efficacy and safety.

\section{Materials and Methods}

Over seven years, all patients presented with appendicular mass were involved in the study. The diagnosis of the appendicular mass was made by clinical examination (acute painful tender mass in the right iliac fossa as in Figure 1,2 usually associated with fever, malaise and anorexia.) and confirmed by ultrasound. Sometimes CT was used in the diagnosis as in Figure 3. The patients were divided into four groups. In group (A) the conservative management (OchsnerSherren regime [5] was applied with routine elective appendectomy after at least six weeks as a routine weather complaining or not. Group (B) conservative treatment was done without elective appendectomy as a routine. Group $(\mathrm{C})$ operative interference at the initial diagnosis was the treatment chosen. Group (D) laparoscopic exploration was done at the initial management procedure.

In group A \& B all patients followed Ochsner-Sherren regime initially, which included; Admission and nursing the patient in a popped-up position encouraging gravitational flow of any exudates towards the pelvis. Nothing is to be given by mouth for an initial 2448 hours while the patient is kept on intravenous fluids, intravenous antibiotics (third generation cephalosporin), regular monitoring of vital sign a as well as local and general signs, and ultrasound follow 
Table 1: Group A: cases with conservative management and routine interval.

\begin{tabular}{|c|c|c|c|c|c|c|c|c|c|c|c|c|c|}
\hline \multirow{2}{*}{$\begin{array}{c}\text { No of } \\
\text { Patients }\end{array}$} & \multirow{2}{*}{$\begin{array}{l}\text { Efficacy; } \\
\text { Successful } \\
\text { Failed }\end{array}$} & \multicolumn{5}{|c|}{ Difficulties encountered during appendectomy } & \multirow{2}{*}{$\begin{array}{l}\text { Post Operative } \\
\text { Complication }\end{array}$} & \multicolumn{3}{|c|}{$\begin{array}{l}\text { Hospital Stay } \\
\text { (total) }\end{array}$} & \multicolumn{3}{|c|}{$\begin{array}{c}\text { Total Duration of } \\
\text { Treatment }\end{array}$} \\
\hline & & $\begin{array}{l}\text { Time in } \\
\text { (minutes) }\end{array}$ & Consultant & Complication & $\begin{array}{l}\text { Appendectomy } \\
\text { or Drainage }\end{array}$ & $\begin{array}{c}\text { Other } \\
\text { Diagnosis }\end{array}$ & & C & O & $\mathbf{T}$ & C & 0 & $\mathbf{T}$ \\
\hline 1 & succeed & 60 & No & No & Appendectomy & No & No & 5 & 1 & 6 & 10 & 7 & 17 \\
\hline 2 & succeed & 50 & No & No & Appendectomy & No & No & 4 & 2 & 6 & 10 & 5 & 15 \\
\hline 3 & succeed & 50 & No & No & Appendectomy & No & yes & 5 & 1 & 6 & 9 & 7 & 16 \\
\hline 4 & succeed & 45 & No & No & one setting & No & No & 6 & 1 & 7 & 14 & 10 & 24 \\
\hline 5 & failed & 110 & yes & No & Appendectomy & & yes & 3 & 7 & 10 & 3 & 18 & 21 \\
\hline 6 & succeed & 100 & yes & No & Appendectomy & No & No & 4 & 1 & 5 & 12 & 5 & 17 \\
\hline 7 & succeed & 35 & No & No & Appendectomy & No & No & 5 & 1 & 6 & 15 & 4 & 19 \\
\hline 8 & succeed & 50 & No & No & Appendectomy & No & No & 6 & 1 & 7 & 13 & 3 & 16 \\
\hline 9 & failed & 60 & No & No & one setting & No & yes & 3 & 4 & 7 & 3 & 16 & 19 \\
\hline 10 & succeed & 40 & No & No & Appendectomy & No & No & 4 & 1 & 5 & 11 & 3 & 14 \\
\hline 12 & succeed & 80 & No & No & Appendectomy & No & No & 3 & 1 & 4 & 9 & 5 & 14 \\
\hline 13 & succeed & 60 & No & No & Appendectomy & No & No & 2 & 1 & 3 & 12 & 3 & 15 \\
\hline 14 & succeed & 70 & No & No & Appendectomy & No & No & 5 & 2 & 7 & 12 & 5 & 17 \\
\hline 15 & succeed & 70 & No & No & Appendectomy & No & No & 4 & 1 & 5 & 10 & 7 & 17 \\
\hline 16 & succeed & 85 & No & No & Appendectomy & No & No & 6 & 1 & 7 & 13 & 5 & 18 \\
\hline 17 & failed & $60+70$ & yes & No & two setting & No & yes & 4 & $5+3$ & 12 & 22 & 8 & 30 \\
\hline 18 & succeed & 90 & No & No & Appendectomy & No & No & 4 & 3 & 7 & 12 & 5 & 17 \\
\hline 19 & succeed & 75 & No & No & Appendectomy & No & No & 4 & 1 & 5 & 14 & 7 & 21 \\
\hline 20 & succeed & 60 & No & No & Appendectomy & No & No & 6 & 1 & 7 & 14 & 5 & 19 \\
\hline 21 & succeed & 50 & No & No & Appendectomy & No & No & 7 & 1 & 8 & 15 & 5 & 20 \\
\hline 22 & succeed & 40 & No & No & Appendectomy & No & No & 5 & 1 & 6 & 13 & 5 & 18 \\
\hline 25 & succeed & 60 & No & No & Appendectomy & No & No & 4 & 1 & 5 & 14 & 3 & 17 \\
\hline 26 & succeed & 50 & No & No & Appendectomy & No & No & 5 & 1 & 6 & 13 & 4 & 17 \\
\hline 27 & succeed & 80 & No & No & Appendectomy & No & yes & 6 & 1 & 7 & 13 & 3 & 16 \\
\hline 28 & succeed & 70 & No & No & Appendectomy & No & No & 6 & 1 & 7 & 14 & 3 & 17 \\
\hline 29 & succeed & 75 & No & No & Appendectomy & No & No & 4 & 1 & 5 & 16 & 2 & 18 \\
\hline 30 & succeed & 80 & yes & No & Appendectomy & No & No & 5 & 2 & 7 & 15 & 5 & 20 \\
\hline 31 & failed & $70+60$ & No & No & two setting & No & yes & 3 & $4+2$ & 9 & 3 & 21 & 24 \\
\hline 32 & succeed & 60 & No & No & Appendectomy & No & No & 3 & 1 & 4 & 10 & 5 & 15 \\
\hline 33 & succeed & 70 & No & No & Appendectomy & No & No & 5 & 1 & 6 & 15 & 4 & 19 \\
\hline 34 & succeed & 45 & No & No & Appendectomy & No & No & 5 & 1 & 6 & 14 & 4 & 18 \\
\hline 35 & succeed & 40 & No & No & Appendectomy & No & No & 4 & 1 & 5 & 13 & 6 & 19 \\
\hline 36 & succeed & 80 & No & No & Appendectomy & No & No & 3 & 2 & 5 & 13 & 5 & 18 \\
\hline 37 & succeed & 80 & No & No & Appendectomy & & No & 5 & 1 & 6 & 15 & 4 & 19 \\
\hline 38 & failed & 50 & yes & No & one setting & No & yes & 2 & 5 & 7 & 2 & 14 & 16 \\
\hline 39 & succeed & 60 & No & No & Appendectomy & No & No & 5 & 1 & 6 & 10 & 4 & 14 \\
\hline 40 & succeed & 45 & No & No & Appendectomy & No & No & 3 & 1 & 4 & 10 & 3 & 13 \\
\hline 41 & succeed & 60 & No & No & Appendectomy & No & No & 2 & 2 & 4 & 9 & 4 & 13 \\
\hline \multirow[t]{4}{*}{42} & succeed & 40 & No & No & Appendectomy & No & No & 6 & 1 & 7 & 13 & 5 & 18 \\
\hline & & 2530 & & & & No & No & 5 & 1 & 6 & 16 & 4 & 20 \\
\hline & \multirow{2}{*}{$\begin{array}{l}\text { Successful in } \\
37(88 \%)\end{array}$} & \multirow[b]{2}{*}{65 m (1hr) } & \multirow{2}{*}{$\begin{array}{l}3(7 \%) \text { need } \\
\text { consultant }\end{array}$} & \multirow[b]{2}{*}{0} & \multirow{2}{*}{$\begin{array}{l}\text { Appendectomy in } \\
100 \% 2(4.7 \%) \text { in } \\
\text { two stages }\end{array}$} & \multirow{2}{*}{$\begin{array}{c}1(\sim 2 \%) \\
\text { hidden } \\
\text { diagnosis }\end{array}$} & \multirow{2}{*}{$\begin{array}{c}4(9.5 \%) \\
\text { complication } \\
\text { minor (SSI) }\end{array}$} & & & $6 d$ & & & $18 d$ \\
\hline & & & & & & & & \multicolumn{6}{|c|}{$\begin{array}{l}\text { C; Conservative period, } \mathrm{O} \text {; operative } \\
\text { period, } \mathrm{T} \text {; total duration }\end{array}$} \\
\hline
\end{tabular}


Table 2: Group B: Conservative management without routine interval appendectomy.

\begin{tabular}{|c|c|c|c|c|c|c|c|c|c|}
\hline \multirow{2}{*}{$\begin{array}{c}\text { No of } \\
\text { Patients }\end{array}$} & \multirow{2}{*}{$\begin{array}{l}\text { Efficacy; } \\
\text { Successful } \\
\text { Failed }\end{array}$} & \multirow{2}{*}{$\begin{array}{c}\text { Evidence } \\
\text { of other } \\
\text { Diagnostics }\end{array}$} & \multirow[b]{2}{*}{ Recurrence } & \multicolumn{4}{|c|}{ Difficulties encountered during operative cases } & \multirow{2}{*}{$\begin{array}{l}\text { Hospital Stay } \\
\text { (Total) }\end{array}$} & \multirow{2}{*}{$\begin{array}{c}\text { Total Duration } \\
\text { of the } \\
\text { Treatment }\end{array}$} \\
\hline & & & & Time in Minutes & Consultant & $\begin{array}{c}\text { Surgical } \\
\text { Interference }\end{array}$ & Complications & & \\
\hline 1 & Succeed & No & No & & & & & 3 & 10 \\
\hline 2 & Succeed & No & Yes & 70 & yes & Appendectomy & No & $3+2(5)$ & 18 \\
\hline 3 & Succeed & No & No & & & No & & 5 & 10 \\
\hline 4 & Succeed & No & No & & & No & & 6 & 13 \\
\hline 5 & Succeed & No & No & & & No & & 4 & 11 \\
\hline 6 & Succeed & No & No & & & No & & 4 & 14 \\
\hline 7 & Succeed & No & No & & & No & & 5 & 10 \\
\hline 8 & Succeed & No & No & & & No & & 3 & 8 \\
\hline 9 & Succeed & No & No & & & No & & 4 & 9 \\
\hline 10 & Failed & $\begin{array}{l}\text { Cecal Mass ( } \\
\text { cancer) }\end{array}$ & & 150 & No & Rt hemi-celotomy & No & $2+10(12)$ & 22 \\
\hline 11 & Failed & No & & 120 & No & Appendectomy & Yes & $4+5(9)$ & 16 \\
\hline 12 & Succeed & No & No & & & No & & 6 & 11 \\
\hline 13 & Succeed & No & No & & & No & & 7 & 14 \\
\hline 14 & Succeed & No & No & & & No & & 8 & 13 \\
\hline 15 & Succeed & No & No & & & No & & 5 & 10 \\
\hline 16 & Succeed & No & No & & & No & & 4 & 11 \\
\hline 17 & Succeed & No & No & & & No & & 3 & 8 \\
\hline 18 & Succeed & No & No & & & No & & 5 & 10 \\
\hline 19 & Failed & No & & 100 & No & Appendectomy & No & 7 & 14 \\
\hline 20 & Succeed & No & No & & & No & & 4 & 10 \\
\hline 21 & Succeed & No & No & & & No & & 5 & 12 \\
\hline 24 & Succeed & No & No & & & No & & 3 & 10 \\
\hline 25 & Succeed & No & No & & & No & & 2 & 7 \\
\hline 26 & Succeed & No & No & & & No & & 4 & 11 \\
\hline 27 & Succeed & No & No & & & No & & 4 & 14 \\
\hline 28 & Failed & No & & $90+60(150)$ & & $\begin{array}{l}\text { Drainge then } \\
\text { Appendectomy }\end{array}$ & & $5+6+1(12)$ & 35 \\
\hline 29 & Succeed & No & Yes & 120 & No & Appendectomy & No & $6+1(7)$ & 18 \\
\hline 30 & Succeed & No & No & & & No & & 6 & 11 \\
\hline 31 & Succeed & No & No & & & No & & 4 & 11 \\
\hline 32 & Succeed & No & No & & & No & & 4 & 14 \\
\hline 33 & Succeed & No & No & & & No & & 7 & 12 \\
\hline 34 & Failed & No & & 100 & & Appendectomy & No & $2+5(7)$ & 17 \\
\hline 35 & Succeed & No & No & & No & No & & 3 & 10 \\
\hline 36 & Succeed & No & No & & & No & & 5 & 15 \\
\hline 37 & Succeed & No & No & & & No & & 4 & 11 \\
\hline 38 & Succeed & No & No & & & No & & 8 & 13 \\
\hline 39 & Succeed & No & No & & & No & & 7 & 12 \\
\hline 40 & Succeed & No & No & & & No & & 3 & 10 \\
\hline 41 & Succeed & No & No & & & No & & 4 & 10 \\
\hline 42 & Succeed & No & No & & & No & & 4 & 10 \\
\hline 43 & Succeed & No & No & & & No & & 5 & 12 \\
\hline
\end{tabular}




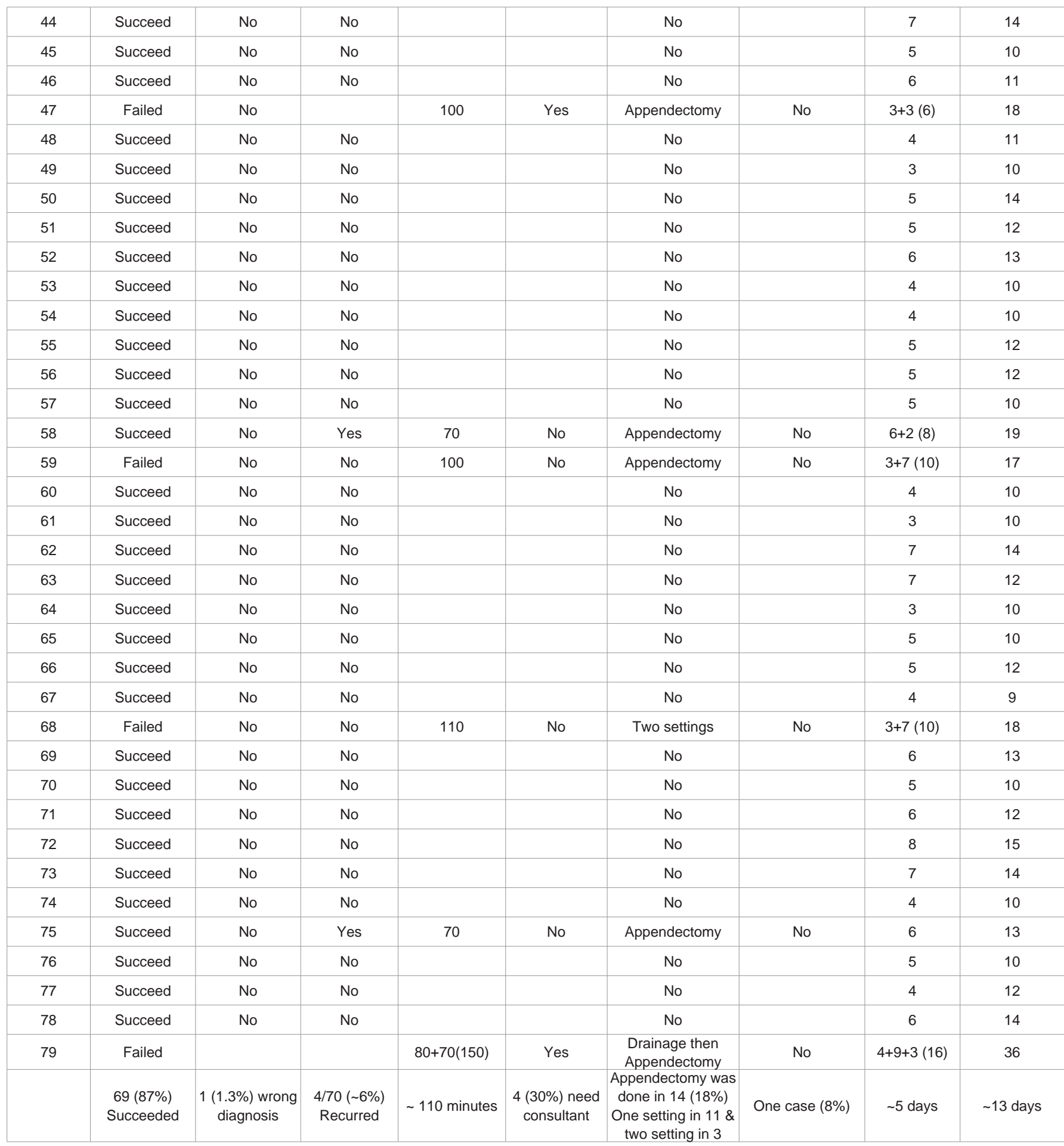

up. If the patient improved, he was allowed to start fluidly then semisolid diet, and discharged home. On the other hand, if patient not responding well or deteriorates, then the conservative management was curtailed and the patient was considered for operation.

The study compared the different modalities of management in terms of efficacy and safety. The safety was evaluated by assessment of occurrence of complications \& difficulties encountered in operative groups $(C, D)$, and failed patients in groups $(A \& B)$ that admitted for operative explorations). We assessed the time of the operation, the need for a consultant \& inability to remove the appendix in the same setting, as well as intraoperative mishaps, to give an idea about the difficulties. While in the conservative groups $(A \& B)$ the safety was evaluated by the failure rate, and difficulties encountered in operative interference in failed cases, the presence of other hidden diagnosis. On the other hand the efficacy was evaluated by the assessment the ability to provide definitive treatment and re need for medical care. Assessment of hospital stays \& duration of treatment were also done. 
Table 3: Group C: Cases with operative interference.

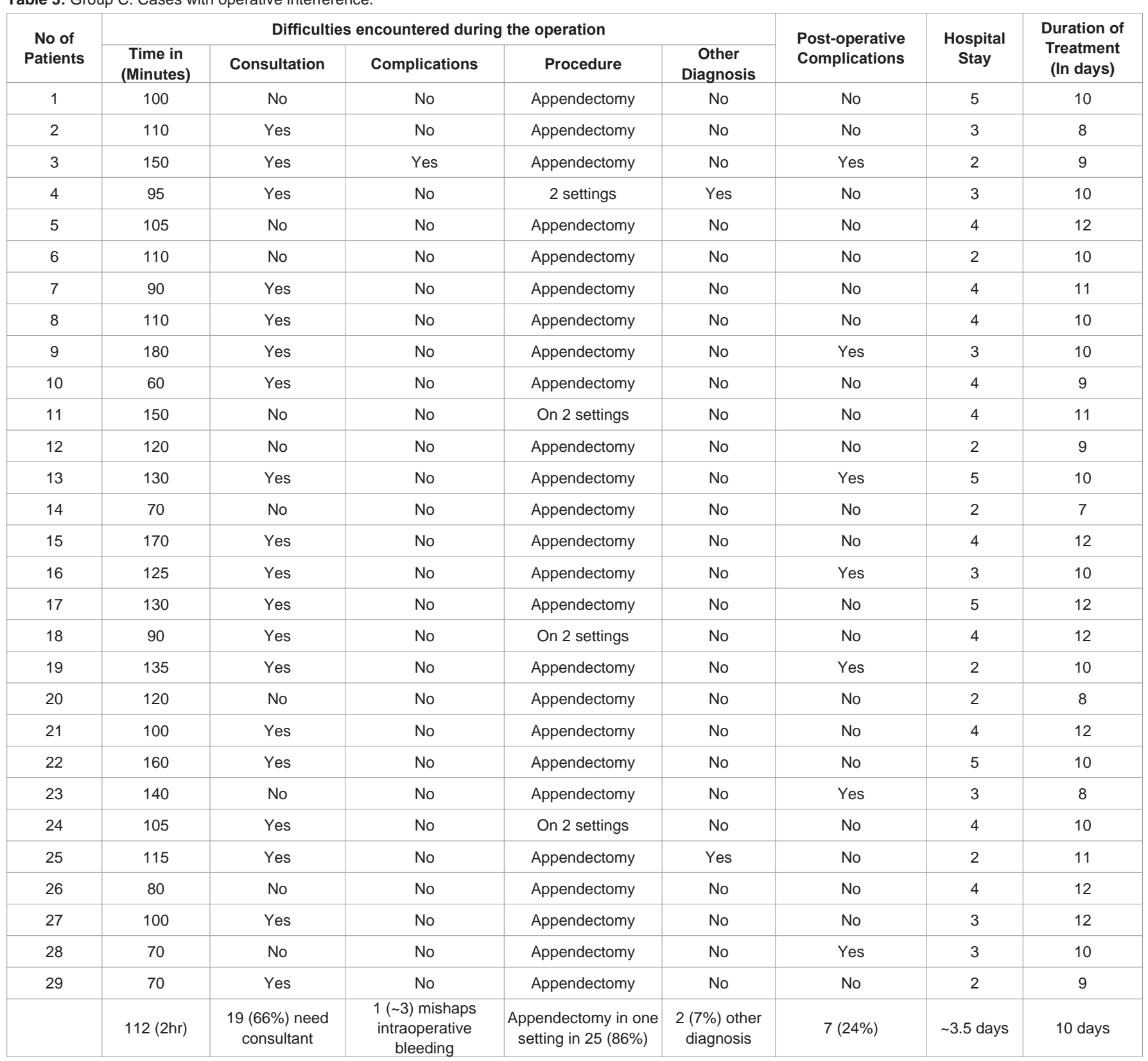

Exclusion criteria include; patients presented initially with abscess (diagnosed clinically \& or imaging study), \& patients lost in follow up.

The average time of follow up was 3.5 years with a minimum two years.

\section{Results}

One hundred and sixty nine (169) cases were presented in this study. Forty two cases involved in group A, seventy nine in group B, twenty nine cases in group $\mathrm{C}$, and nineteen patients in group D.

Group A included forty two patients shown in Table 1. Conservative management was successful in $37(88 \%)$ patients and failed in five cases $(12 \%)$. One case $(\sim 2 \%)$ was mis-diagnosed as appendicular mass and discovered during operative interference (after failure of conservative measures) to be iliocecal mass (proved to be GIST), where right hemi-colictomy was done. Surgical interference with appendectomy was done in five cases (12\%) because of failure of conservative treatment. Two patients required two settings (drain then appendectomy) and three in one settings. The remaining cases (37) appendectomy was done as a routine after at least six weeks. The average total hospital stay in this group was six days and the average duration of medical treatment was about eighteen days. On reviewing the operative details; the average time was about one hours, consultant was needed in three cases $(\sim 7 \%)$. No intraoperative mishaps or complication was noted, but four cases ( $\sim 9.5 \%)$ developed minor postoperative complications in the form of Surgical Site Infection (SSI) that treated medically. 
Table 4: Group D: Cases with laproscopic interference.

\begin{tabular}{|c|c|c|c|c|c|c|c|c|c|}
\hline \multirow{2}{*}{ No of Patients } & \multicolumn{6}{|c|}{ Difficulties encountered during the operation } & \multirow{2}{*}{$\begin{array}{l}\text { Post-operative } \\
\text { Complications }\end{array}$} & \multirow{2}{*}{$\begin{array}{c}\text { Hospital } \\
\text { Stay } \\
\text { (Total) }\end{array}$} & \multirow{2}{*}{$\begin{array}{l}\text { Duration of } \\
\text { Treatment } \\
\text { (In days) }\end{array}$} \\
\hline & Time & Consultant & Complications & Conversion & Procedure & $\begin{array}{c}\text { Other } \\
\text { Diagnosis }\end{array}$ & & & \\
\hline 1 & 90 & yes & No & No & Appendectomy & No & No & 2 & 8 \\
\hline 2 & 100 & yes & No & No & Appendectomy & No & Yes & $3+2(5)$ & 16 \\
\hline 3 & 80 & yes & No & No & Drainage only & No & No & 1 & 7 \\
\hline 4 & 120 & yes & No & No & Appendectomy & Yes & No & 2 & 12 \\
\hline 5 & 180 & yes & No & No & Appendectomy & No & No & 2 & 6 \\
\hline 6 & 90 & yes & No & No & Appendectomy & No & No & 1 & 4 \\
\hline 7 & 90 & yes & No & No & Appendectomy & No & No & 2 & 5 \\
\hline 8 & 60 & yes & No & No & Appendectomy & No & No & 1 & 8 \\
\hline 9 & 80 & yes & No & No & Drainage only & No & No & $2+2(4)$ & 13 \\
\hline 11 & 70 & yes & No & No & Drainage only & No & No & $3+2(5)$ & 15 \\
\hline 12 & 110 & yes & No & No & Appendectomy & No & No & 2 & 4 \\
\hline 13 & 70 & yes & No & No & Appendectomy & No & No & 1 & 7 \\
\hline 14 & 100 & yes & No & No & Drainage only & No & No & $2+1(3)$ & 13 \\
\hline 15 & 90 & yes & No & No & Appendectomy & No & No & 3 & 9 \\
\hline 16 & 80 & yes & No & No & Appendectomy & No & No & 2 & 6 \\
\hline 17 & 110 & yes & No & No & Appendectomy & No & No & 2 & 7 \\
\hline 18 & 80 & yes & No & No & Appendectomy & No & No & 3 & 8 \\
\hline \multirow[t]{2}{*}{19} & 90 & yes & No & No & Drainage only & No & No & $3+2(5)$ & 12 \\
\hline & $90 \mathrm{~m}$ (1.5hr) & $\begin{array}{c}\text { all cases need } \\
\text { consultant }\end{array}$ & No & No & $\begin{array}{l}\text { One setting in } 14 \\
(73 \%) \& 5(27 \%)\end{array}$ & $\begin{array}{c}1(5 \%) \text { other } \\
\text { diagnosis }\end{array}$ & $\begin{array}{c}2(10 \%) \\
\text { complications }\end{array}$ & $2.5 d$ & $\sim 9$ day \\
\hline
\end{tabular}

Table 5: Comparative study between four groups.

\begin{tabular}{|c|c|c|c|c|c|c|c|c|c|}
\hline \multirow{2}{*}{$\begin{array}{c}\text { Modalities of } \\
\text { Treatment }\end{array}$} & \multirow[b]{2}{*}{ Efficacy } & \multirow{2}{*}{$\begin{array}{c}\text { Other } \\
\text { Diagnosis }\end{array}$} & \multicolumn{5}{|c|}{ Difficulties encountered during operative cases } & \multirow{2}{*}{$\begin{array}{c}\text { Hospital } \\
\text { Stay (Total) }\end{array}$} & \multirow{2}{*}{$\begin{array}{c}\text { Total } \\
\text { duration of } \\
\text { Treatment }\end{array}$} \\
\hline & & & $\begin{array}{l}\text { Time in } \\
\text { Minutes }\end{array}$ & $\begin{array}{l}\text { Consultant is } \\
\text { needed in }\end{array}$ & Appendectomy & Complication & $\begin{array}{l}\text { Post-operative } \\
\text { Complication }\end{array}$ & & \\
\hline Group A & $\begin{array}{l}\text { Successful in } 37 \\
(88 \%) \text {. } \\
\text { Failed in } 5(12 \%)\end{array}$ & $1(\sim 2 \%)$ & $65 \mathrm{~m}(1 \mathrm{hr})$ & $3(7 \%)$ & $\begin{array}{c}\text {-done in all cases } \\
-2(4.7 \%) \text { in two } \\
\text { stages }\end{array}$ & No & $4(9.5 \%)$ & 6 & 18 \\
\hline Group B & $\begin{array}{l}\text { *successful in } 69 \\
(87 \%) \\
\text { *Failed in } 13 \% \\
\text { *Recurrence in } 4 \\
\text { cases }(6 \%) \\
\text { *Eventual } \\
\text { appendectomy } \\
\text { in } 14 \text { cases } \\
(18 \%) \text { and } 82 \% \\
\text { of cases saved } \\
\text { appendectomy } \\
\text { *Recurrence in } \\
6 \% 4 \text { cases }\end{array}$ & $1(1.3 \%)$ & 110 & $4(33 \%)$ & $\begin{array}{l}\text {-done in } 12 \text { patients } \\
(15 \%) \\
-4 \% \text { of patients in } 2 \\
\text { setting }\end{array}$ & No & One $(8 \%)$ & 5 & 13 \\
\hline Group C & $\begin{array}{l}\text { *successful in } \\
\text { one setting in } 25 \\
(86 \%) \\
\text { *14 }\end{array}$ & $2(7 \%)$ & $112(2 \mathrm{hr})$ & $19(66 \%)$ & $\begin{array}{c}\text {-done in } 100 \% \\
-1 \text { setting in } 25 \\
(86 \% 0 \\
-2 \text { setting in } 14 \%\end{array}$ & $1(\sim 3 \%)$ & $7(24 \%)$ & 3.5 & 10 \\
\hline Group D & & $1(5 \%)$ & 90 & $100 \%$ & $\begin{array}{c}-1 \text { setting in } 14 \\
(73 \%) \\
-2 \text { setting in } 5 \\
(27 \%)\end{array}$ & No & $2(10 \%)$ & 2.5 & 9 \\
\hline
\end{tabular}

Group B included seventy nine cases shown in Table 2. Conservative management was successful in $69(87 \%)$ and failed in ten cases (13\%). One case (1.3\%) was cecal mass (adenocarcinoma) that mis-diagnosed as appendicular mass. It was discovered during operative interference after failure of conservative measures where right hemi-colectomy was done. Recurrence of the attacks occurred in four cases (6\%) where appendectomy was done. Surgical interference was done in fourteen cases ( $18 \%)$; four cases for recurrent attacks \& 


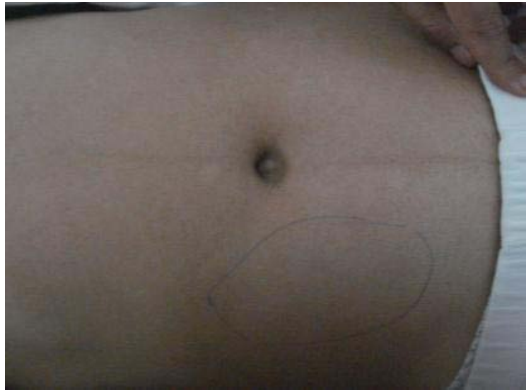

Figure 1: Clinically palpable appendicular mass in male.

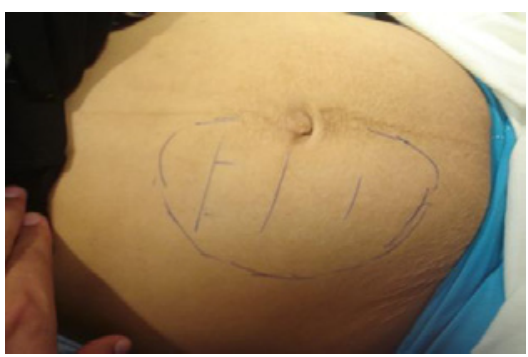

Figure 2: Clinically palpable appendicular mass in female.

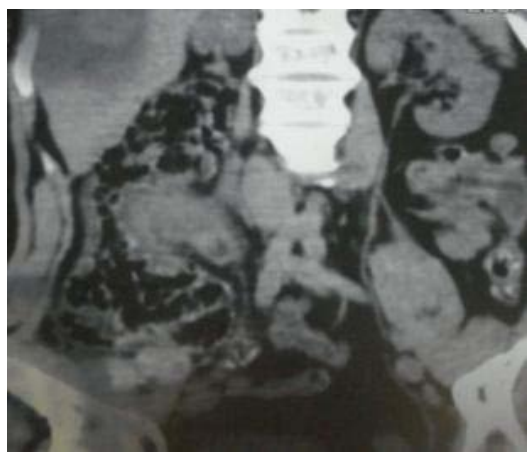

Figure 3: CT demonstrating appendicular mass.

ten for failure of conservative treatment. In this group appendectomy was done in one setting in twelve cases \& three cases $(\sim 4 \%)$ were done in two settings (drainage then appendectomy). The average total hospital stay was about 5 days and the average duration of medical treatment was about thirteen days. The details of operative cases entailed; average operative time of approximately two hours, with the consultant was requested in about one third of the cases. One case (8\%) of SSI developed and controlled medically.

Group C involved twenty nine cases shown in Table 3. Appendectomy was done in one setting in 25 cases (86\%) and in two settings in four cases (14\%). The mean time of the operation was about two hours, with a need of consultant in nineteen cases (66\%). Intraoperative bleeding (mild) occurred in one case (3\%) and controlled. Two cases $(\sim 7 \%)$ were found to have another diagnosis during explorations (iliocecal lymphoma \& Crhon`s disease of the appendix Figure 3). Seven cases developed complications (24\%); one seroma, five SSI treated medically, and one incisional hernia which repaired one year later on. The total hospital stay was approximately

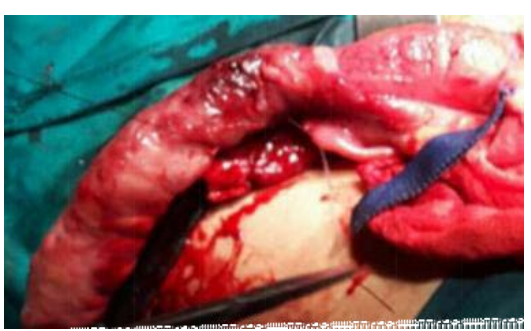

Figure 4: Chron's disease presented as appendicular mass.

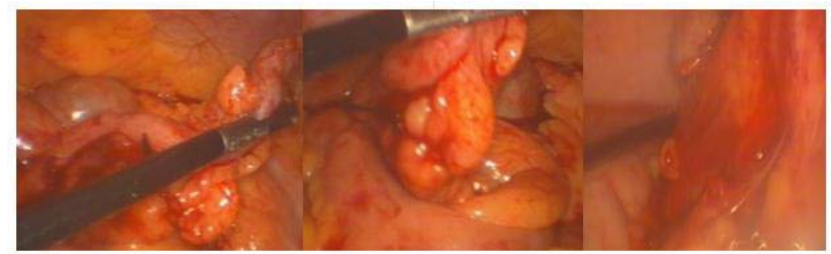

Figure 5: Laparoscopic adhesiolysis of appendicular mass.

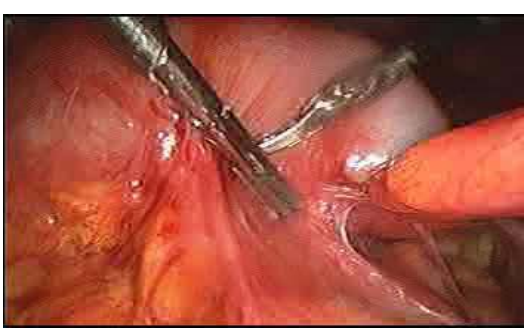

Figure 6: Right salpingio-oopheritis with amalgamated omentum and bowe mimic appendicular mass.

3.5 days while the average total duration of treatment was ten days.

Group D included nineteen cases shown in Table 4, Figure 5a-5c. Appendectomy was done in one setting in 14 cases $(73 \%)$ and in two settings in five cases (27\%). The mean time of the operation was about 1.5 hours, with a need of consultant in all cases. No intraoperative complication or conversion to open surgery occurred

One case $(\sim 5 \%)$ was found to have another diagnosis during explorations (right salpingoopheritis with amalgamated omentum Figure 6). Two cases developed post-operative complications (10\%) in the form of minor SSI that treated medically. The total hospital stay was approximately 2.5 days while the average total duration of treatment was less than nine days.

On comparing \& reviewing the data in the four groups as shown in Table 5 we found that, the conservative management was applied in 121 patients (patients in group $\mathrm{A} \& \mathrm{~B}$ ) and it was successful in 106 patients $(\sim 88 \%)$ and failed in 15 patients $(\sim 12 \%)$. Other pathology rather than appendicular mass was found in five cases in all groups ( $\sim 3 \%$ of all cases) that misdiagnosed as appendicular inflammatory mass. Appendectomy was done in all (100\%) patients of group A, C \& $\mathrm{D}$, and only in 14 patients (18\%) in group B, with $82 \%$ of the patients in this group saved appendectomy without any harm. Appendectomy was done in two settings (drainage then appendectomy) in $5 \%$ of group A, $4 \%$ of group B, $14 \%$ of group C, and $27 \%$ of patients in 


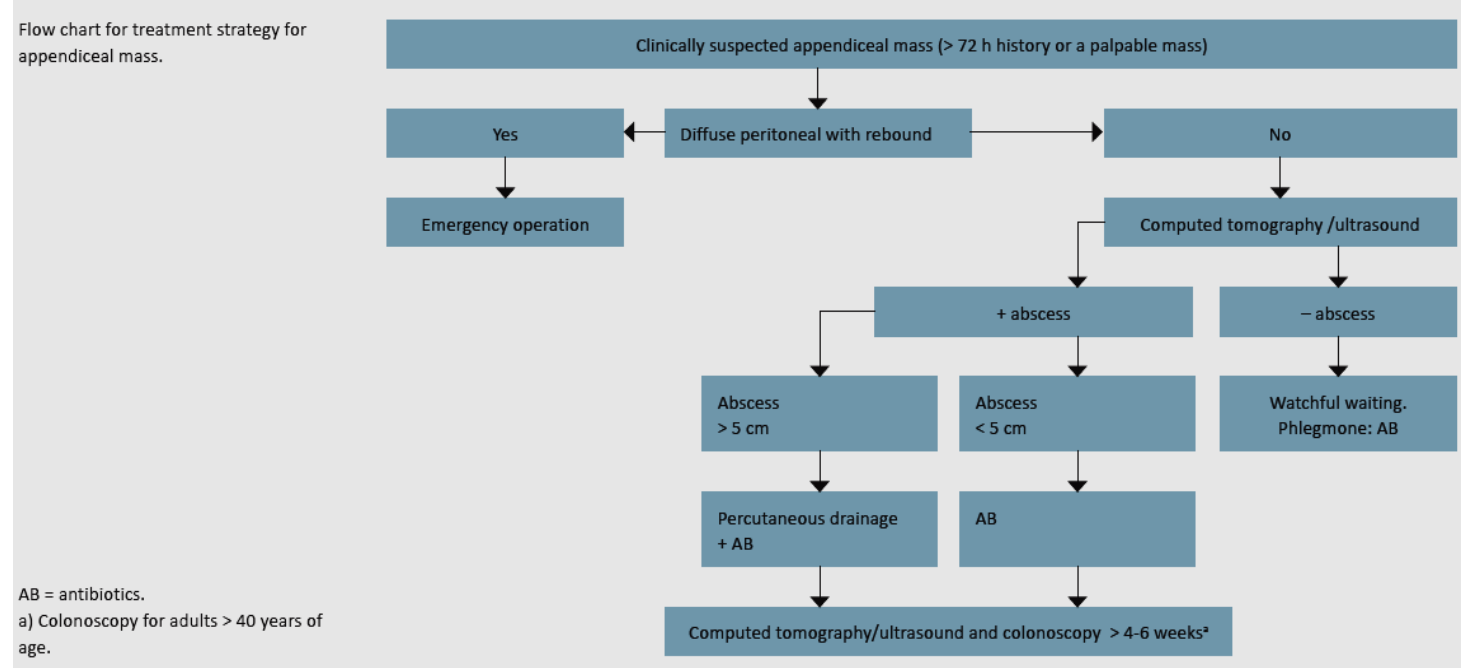

Figure 7: Flow chart for treatment strategy for appendicular mass [7].

group D. Hospital stay \& duration of treatment were $>2$ folds more in conservative groups $(\mathrm{A} \& \mathrm{~B})$ than intervention groups $(\mathrm{C} \& \mathrm{D})$. Difficulties in operations were reported more in intervention groups (C\&D), where consultant was needed in all cases of group $D, 2 / 3$ of group B, and only $1 / 3$ of group B \& $7 \%$ in group A. The average operative was in insignificant in four groups ranging from 1.5 to 2 hours. This may be attributed to rapid decision in difficult cases to put a drain and complete the procedure in two stages. Complications were more in group C $24 \%$ but most of them were minor. There was no significant difference in operative difficulties between patient failed conservative measures and interventional group from the start (group C\&D).

\section{Discussion}

The lifetime probability for the development of appendicitis is $8.6 \%$ in males \& $6.7 \%$ in females [3]. Approximately $7 \%$ of these patients will develop appendicular mass [6], especially with development of strong antibiotic [2]. This usually occurs after 48-72 hours of the first symptoms of acute appendicitis [7]. As a natural protective mechanism, the omentum \& small bowel wrap around the inflamed appendix to isolate it from the rest of the abdominal cavity preventing spread of infection [8] \& forming the components of the mass [9]. This usually becomes palpable in the right iliac fossa by the third day [10]. There are no universal standard or clear-cut guidelines in the management of the appendicular mass with extreme modalities of treatment [5]. Currently there are four modes of treatment practiced all over the world which include [11].

Initial conservative approach followed by routine interval appendectomy 6-8 weeks later [12]. This is the traditional \& the most commonly practiced approach in the absence of abscess formation [7]. It is trusted \& favored widely all over the world because of; its efficacy \& safety [13], with avoidance of the potential hazards of intestinal injuries [14]. The success rate ranges from 88-95\%31, with substantially low rate of complications [14]. Surgeon preference remains a common reason [15]. Interval appendectomy is considered here to be essential, believing that the rate of recurrent appendicitis is high [16]. Interval appendectomy is a safer \& easier procedure than to do appendectomy in the initial admission [17].

Early appendectomy once diagnosed, using either open or laparoscopic technique [18]. Those advocate this approach consider the avoidance of; misdiagnosis (or hidden other pathology), more demanding operative interference when the conservative management failed, and repeated admissions of the recurrent attacks that ultimately required appendectomy after frequent admission [19]. Some studies provided this approach as a safer feasible one with no significant harm [20]. Laparscopic approach provides minimal invasive modality with less hospital stay and rapid recovery [21], however it needs expert to manipulate the intestines and dissect the mass safely.

Semi conservative approach with immediate appendectomy after clinical improvement during the initial [22]. This team considered the advantages of early appendectomy mentioned before. They claimed that it is safer than immediate appendectomy. However, there no studies support difference in safety between immediate appendectomy and early appendectomy after initial treatment [22].

Entirely conservative treatment without routine interval appendectomy. Those advocate this approach consider the advantages of initial conservative management in terms of efficacy and safety [23]. It is argued that interval appendectomy is unnecessary [10] after successful conservative management of an appendicular mass because of low rate of recurrence [24]. They recommend the interval appendectomy only in patients exhibiting recurrent attacks [25]. In addition, the appendix may be fibrotic [26] \& may not be $\mathrm{f}$ ound on operation which may make some of the routine interval appendectomy difficult [27]. This has led to the concept of a "wait and watch policy" after successful conservative management and has been found to be cost effective [28]. Those advocates of this approach may go as far as to propose that recurrent disease is also amenable to conservative treatment and is cost effective [8].

The greatest risk of developing recurrent appendicitis after successful conservative management is during the first 6 months and 
there is a minimal chance for developing the symptoms after 2 years [29].

This study documented the efficacy of the four modalities of management either conservative or interventional. The conservative approach is quiet effective one with success rate of about $88 \%$. Patients who failed conservative approach, had no significant difference with interventional groups $(C \& D)$ in terms of operative time, need of expert, occurrence of complications. Appendectomy was documented in this study to be unnecessary in $82 \%$ of patients of conservative approach without any harm to the patients. So $82 \%$ of the patients in this group saved un-necessary interference. The rate of recurrence in conservative approach was too low to be a burden, only $6 \%$ of the patients with less significant difference in operative difficulties compared to other groups (C\&D).

The amalgamated bowels and omentum make the adhesiolysis and dissection of the mass difficult, which may end the surgical interference by drainage alone and postpone appendectomy in other stage to ensure safety of the patients. The risk to do appendectomy in two stages (drainage then appendectomy) was high in interventional group specially the laparoscopic one. However, the hospital stay and duration of treatment were markedly reduced in interventional groups specially the laparoscopic one. Although the complications of all groups were minor but still the open operative approach carried more risk than other groups to develop them (more than two folds).

In the literature many studies confirmed the un-necessity of routine elective appendectomy [6], reporting that most of the patients don't usually suffered from repeated attacks $[10,29,30]$. Jesper Olsen et al assessed the various treatment modalities with respect to complications and treatment failure through the analysis of a qualitative systematic review in literatures from 1966 to March 2014 and recommend conservative approach \& watchful seeing policy for appedicular mass without evidence of abscess formation \& recommend step down strategy according to the presentation of the patients as in Figure 7, [7].

Although the advantages of conservative approach, the presence of $3 \%$ of cases in this study with other diagnosis emphasis on the importance to do detailed investigations even after relive of the attack to be sure that there is no hidden pathology in the conservative groups. CT, MRI, and colonoscopy may be beneficial here.

The laparoscopic approach seem to be growing and hoping approach with less complication and hospital stays and durations of treatment as well as discovery of other pathology and early drainage of possible abscess and may be with growing learning curve a change in the curve may be done.

\section{Conclusion}

Although there is a debate in the best modalities of treatment of appendicular mass, the conservative approach is a quite effective \& safe method of treatment, with no significant operative difficulties in failed group. The rate of recurrence after successful conservative management is low to justify interval appendectomy as a routine. Appendectomy should be restricted to the few cases exhibiting recurrent appendicitis. CT \& or colonoscopy is preferred to be done after relief of acute attacks specially in risky patients to avoid missing another pathology. The laparoscopic approach seem to be promising, with early recovery and less hospital stays and durations of treatment as well as diagnostic superiority for a hidden pathology which may become the superior modalities with growing learning curve .

\section{References}

1. Abdelrahman MT, Mourgi AM, Karam AR, Alfaar SF, Alosaimi MA, Alasiri MS A survey of management of appendiceal mass among surgeons: what is best practice? Int Surg J. 2017; 4: 1850-1855.

2. Geofferey F, et al. Appendix. Shakelford's Surgery of the alimentary tract. Steven RD, David w m, Jeffrey B M, et al. Elsevier. 8 ${ }^{\text {th }}$. Edition. 2019; 164; 1951; 1955.

3. Mike KL, Roland EA, Bernard MJ, David HB. Appendix. Schwartz's Principles of Surgery. F. Charles Brunicardi, et al. McGraw-Hill Education. Tenth Edition. 2015; 30: 1243-1250.

4. Abdul-Wahed Nasir Meshikhes. Appendiceal mass: Is interval appendicectomy "something of the past"? World J Gastroenterol. 2011; 17: 2977-2980.

5. M Irfan, AM Hogan, R Gately, AJ Lowery, R Waldron, W Khan, et al. Management of the Acute Appendix Mass: A Survey of Surgical Practice. Ir Med J. 2012; 105: 303-305.

6. Gerard MD. Appendix in Current diagnosis \&treatment. Surgery Gerard M Doherty. $13^{\text {th }}$. Edition. 2010; 28: 615-620.

7. Olsen J, Skovda J, Qvist N. Thue Bisgaard Treatment of appendiceal mass-a qualitative systematic review. Dan Med J. 2014; 61: A4881.

8. Arshad MM, Noshad Ahmad Shaikh. Recent Trends in the Treatment of the Appendicular Mass, Appendicitis-A Collection of Essays from Around the World, Dr. Anthony Lander (Ed). 2012; 5: 87-95.

9. Brian WE, Simon-Paterson-Brown. In Acute appendicitis in Hamilton Baily's emergency surgery. Published by Arnold, $13^{\text {th }}$ Edn. 2000: 399-410.

10. Willemsen PJ, Hoorntje LE, Eddes EH, Ploeg RJ. The need for interval appendectomy after resolution of an appendiceal mass questioned. Dig Surg. 2002; 19: 216-220.

11. Lai HW, Loong CC, Chiu JH, Chau GY, Wu CW, Lui WY, et al. Interval appendectomy after conservative treatment of an appendiceal mass. World J Surg. 2006; 30: 352-357.

12. Hanif SM, Tahir HT, sheikh Al, Ranjha ZM. Acute appendicitis: gaining time in mass casualty scenario. Pak Armed Forces J Med. 2010; 3: 23-25.

13. Cheng Y, Zhou S, Zhou R, Lu J, Wu S, Xiong X, et al. Abdominal drainage to prevent intra-peritoneal abscess after open appendectomy for complicated appendicitis. Cochrane Database Syst Rev. 2015; 2: 20-28.

14. Norman SW, Christopher JKB, P Ronan. O' Connel in Vermiform appendix in Short practice of surgery. Edward Arnold publisher Ltd. 25 $5^{\text {th }}$ ed. 2008; 12051217.

15. Kim JK, Ryoos S, Oh HK, Kim JS, Shin R, Choe EK, et al. Management of appendicitis with abscess or mass. J Korean Soc Coloproctol. 2010; 26: 413-419.

16. Ullah S, Khan M, Ahmad S, Mumtaz N. "Conservative Treatment Of Appendicular Mass Without Interval Appendicectomy: Is It Justified?". JPMI. 2007; 21: 55-59.

17. Meshikhes Aw. "Management of Appendiceal Mass: Controversial Issues Revisited". J Gastrointest Surg. 2008; 4: 767-775.

18. Pandey PC, Kesharwani CR, Chauhan SGC, et al. Management of Appendicular Lump: Early exploration Vs conservative management. Int J Med Sci Public Health. 2013; 2: 1046-1049.

19. MA Bahram. Evaluation of early surgical management of complicated appendicitis by appendicular mass. Int J Surg. 2011; 9: 101-103.

20. De U, Ghosh S. "Acute Appendicectomy For Appendicular Mass: A Study of 87 Patients", Ceylon Med J. 2002; 47: 117-118. 
21. Padankatti LR, Kirthy PR, Gupta A, Ramachandran P. Laparoscopic versus open appendicectomy for complicated appendicitis: A prospective study. J Indian Assoc Pediatr Surg. 2008; 13.

22. Eryilmaz R, Sahin M, SavaÃ MR. Is interval appendectomy necessary after conservative treatment of appendiceal masses? [Article in Turkish]. Ulus Travma Acil Cerrahi Derg. 2004; 10: 185-188.

23. Cunnigaiper Nd, Raj P, Ganeshram $P$, Venkatesan V, "Does OchsnerSherren Regimen Still Hold True In The Management Of Appendicular Mass?". Ulus Travma Acil Cerrahi Derg. 2010; 16: 43-46.

24. Eryilmaz R, Sahin M, Savaa MR. Is interval appendectomy necessary after conservative treatment of appendiceal masses? [Article in Turkish]. Ulus Travma Acil Cerrahi Derg. 2004; 10: 185-188.

25. Prakash CP, Kesharwani CR, Chauhan SGC, Pandey MK, Mittra P, Kumar P, et al. "Management of Appendicular Lump: Early exploration Vs conservative management." International Journal of Medical Science and Public Health. 2013; 1046-1049.
26. Garba ES, Ahmed A. Management of Appendiceal mass. Annals of African Medicine. 2008; 7: 200-204

27. Deakin DE, Ahmed I. Interval appendectomy after resolution of the mass. Is it necessary? The surgeon. 2007; 5: 45-50.

28. Lai WH, Loong CC, Wu WC, Lui YW. Watchful waiting versus interval appendectomy for patients who recovered from acute appendicitis with tumor formation: A cost-effective analysis. J Chin Med Assc. 2005; 68: 431-434.

29. Edward a. Levine, Nathan Mowery. Disease of the appendix. Greenfield`s Surgery. Scientific principles and practice. Micheal w Mulholland, keith d lillemoe, Gerad m Doherty et al, 6 ${ }^{\text {th }}$. Edition wolters Kluwer. 2017; 71: 18881892.

30. E Okune, G Marek, K Jaros?aw. Management of Appendiceal Mass in Children and Adults: Our Experience. The Internet Journal of Surgery. 2006; 9; 157-162.
Austin J Gastroenterol - Volume 6 Issue 1 - 2019

ISSN : 2381-9219 | www.austinpublishing group.com Elsaady. (C) All rights are reserved
Citation: Elsaady A. Management of Appendicular Mass; Comparative Study between Different Modalities. Austin J Gastroenterol. 2019; 6(1): 1097 